\title{
A escolha dos "ungidos": nepotismo e carisma a serviço do poder político-religioso pentecostal
}

\author{
Josué de Souza1
}

RESUMO: O presente trabalho é um desdobramento da pesquisa de mestrado: Religião, Poder Político e Desenvolvimento: Uma leitura a partir de um movimento pentecostal no Estado de Santa Catarina/Brasil - IEAD vinculado ao Programa de Pós-Graduação em Desenvolvimento Regional - PPGDR da Universidade Regional de Blumenau - FURB. Durante a pesquisa buscamos investigar práticas e mecanismos de legitimação sociopolítica pentecostal. A metodologia utilizada foi bibliográfica, documental e social. Foram entrevistados onze lideranças políticas e religiosas vinculados a Convenção das Assembleias de Deus de Santa Catarina e do Sul do Oeste do Paraná (CIADESP) e da Convenção Geral das Assembleias de Deus do Brasil (CGADB). Os resultados apontam que a partir dos anos setenta há no interior do campo religioso pentecostal uma transformação doutrinária que altera o perfil sociológico pentecostal de religião de negação do mundo para religião de afirmação do mundo. Outro fenômeno é estratégias e mecanismos políticos de ocupação de espaço na esfera política. O capital religioso é transformado em capital político. A intersecção destes dois fenômenos é uma das chaves de interpretação do crescente protagonismo político e social dos pentecostais no Brasil. O recorte pretendido no presente trabalho é demonstrar que no campo religioso pentecostal as relações de parentescos incidem no recrutamento e seleção de elites religiosas e políticas.

Palavras-chave: Pentecostalismo. Elite Religiosa. Parentesco.

\section{The choice of the "anointed ones": nepotism and charisma in the service of the pentecostal political-religious power}

\begin{abstract}
The present work is an extension of the master's research: Religion, Political Power and Development: A reading from a Pentecostal movement in the State of Santa Catarina / Brazil - IEAD linked to the Postgraduate Program in Regional Development PPGDR of the Regional University Of Blumenau - FURB. During the research we seek to investigate practices and mechanisms of Pentecostal sociopolitical legitimation. The methodology used was bibliographic, documentary and social. Eleven political and religious leaders were interviewed in connection with the Convention of the Assemblies of God of Santa Catarina and Southern Western Paraná (CIADESP) and the General Convention of Assemblies of God of Brazil (CGADB). The results point out that from the seventies onwards there is a doctrinal transformation within the Pentecostal religious field that changes the Pentecostal sociological profile of the religion of denial of the world to religion of affirmation of the world. Another phenomenon is political strategies and mechanisms of occupation of space in the political sphere. Religious capital is transformed into political capital. The intersection of these two phenomena is one of the keys of interpretation of the growing political and social protagonism of the Pentecostals in Brazil. The aim of this study is to demonstrate that in the Pentecostal religious field, kinship relations focus on the recruitment and selection of religious and political elites.
\end{abstract}

Keywords: Pentecostalism. Religious Elite. Kinship.

- Enviado em 01/05/2017

- Aprovado em 17/05/2017

1 Cientista Social e Mestre em Desenvolvimento Regional - PPGDR da FURB. Docente Departamento de Filosofia e Sociologia da FURB. Docente efetivo da disciplina de Sociologia na Rede Estadual de Educação de SC, atuando na Escola de Educação Básica Elza Pacheco; Professor Substituto do Departamento de Filosofia e Sociologia da Universidade Regional de Blumenau. Integra o Grupo de Pesquisa Ethos, Alteridade e Desenvolvimento (GPEAD) do PPGDR - FURB. Uma versão preliminar desse texto foi apresentada no VIII Seminário Nacional de Sociologia e Política realizado de 17 a 19 de maio de 2017 na UFPR. Email: josuedesouza1@yahoo.com.br 


\section{INTRODUÇÃO}

O presente trabalho é um desdobramento da pesquisa de mestrado: Religião, Poder político e Desenvolvimento: Uma leitura a partir de um movimento pentecostal histórico no Estado de Santa Catarina/Brasil - IEAD. Vincula-se à linha de pesquisa: Estado, Sociedade e Desenvolvimento no Território do Programa de Pós-Graduação em Desenvolvimento Regional PPGDR da Universidade Regional de Blumenau (FURB). Integra o conjunto de estudos e pesquisas do Grupo de Pesquisa Ethos, Alteridade e Desenvolvimento (GPEAD) vinculado a este Programa e Linha de Pesquisa.

A pesquisa de dissertação original foi de cunho qualitativo, utilizou como metodologia a investigação bibliográfica, documental e social. No que se refere aos aspectos teóricos, à investigação movimentou-se dentro de uma perspectiva interdisciplinar nas áreas das humanas. $\mathrm{Na}$ pesquisa social, foram entrevistados onze atores sociais vinculados ao campo religioso e político de liderança na IEAD em Santa Catarina, representado pela Convenção das Assembleias de Deus de Santa Catarina e do Sul do Oeste do Paraná (CIADESP) e da Convenção Geral das Assembleias de Deus do Brasil (CGADB), com a utilização de questões semiestruturadas e não diretivas.

Durante a pesquisa buscamos investigar práticas e mecanismos de legitimação sociopolítica pentecostal. Os resultados apontam que a partir dos anos setenta há no interior do campo religioso pentecostal uma transformação doutrinária que altera o perfil sociológico pentecostal de religião de negação do mundo para religião de afirmação do mundo. Outro fenômeno é estratégias e mecanismos políticos de ocupação de espaço na esfera política. 0 capital religioso é transformado em capital político. A intersecção destes dois fenômenos é uma das chaves de interpretação do crescente protagonismo político e social dos pentecostais no Brasil. O objetivo neste artigo é apontar como no campo religioso pentecostal as relações de parentescos incidem no recrutamento e seleção de elites religiosas e políticas. 


\section{A ASSEMBLEIA DE DEUS NO BRASIL}

Os fundadores do movimento brasileiro foram dois jovens suecos que se conheceram na cidade de Chicago nos EUA. Daniel Berg e Gunnar Vingren têm em comum a origem de famílias pobres que fugiam da Europa em busca de melhores condições de vida e crentes batistas (d'AVILA, 2006; LOPES, 2008)

Sem o apoio da Igreja Batista Americana os dois viajaram para o Brasil sem garantias de sustento (ALMEIDA, 1982). Aportaram em Belém - PA em 19 de novembro de 1910. Foram recebidos pela Igreja Batista de Belém, que segundo Lopes (2008) deu-Ihes "hospedagens e oportunidades para pregar". Para o sustento os missionários venderam Bíblias e Daniel Berg trabalhou em uma fundição. Sete meses depois de chegar ao Brasil a dupla é expulsa da Igreja Batista de Belém juntamente com dezessete pessoas por motivo de sua pregação pentecostal. Após a cisão com a Igreja Batista, Daniel Berg e Gunnar Vingren, juntamente com os membros batistas expulsos fundaram em 18 de Julho de 1911 no Pará a "Missão de Fé Apostólica", que em 11 de Janeiro de 1918, passou a ser chamada de IEAD, por influência do movimento pentecostal americano, que também assumiu este nome.

Segundo Mafra (2001), a forma de organização colocada em prática pelos grupos evangélicos no Brasil, sobretudo os pentecostais, é marcada pela solidariedade, com forte iniciativa individual com um recorte ideológico, muito parecido com a organização da sociedade civil americana, descrito por Tocqueville em "A democracia nas Américas".

Inicialmente marcada por um perfil de Religião de Negação do Mundo, com uma teologia simplificada e assemelhando-se culturalmente ao catolicismo popular, produziu uma capacidade de unir em um só espaço elementos da religiosidade americana e europeia, ou ainda com elementos da religiosidade africana e brasileira.

No primeiro momento a relação criada pelos fundadores do movimento pentecostal em relação ao estado será apolítica e de um verdadeiro afastamento de qualquer comportamento político partidário, sendo inclusive, fator de orgulho para seus fundadores. A política era considerada "coisa do mundo". Pierucci (1996), afirma que a bordão do senso comum "crente não se mete em política" trazia nela duas percepções: a separação de outros grupos, mas também por autodefinição a separação da vida política. 
Saulo Adami e Osmar José da Silva (2011) em uma pequena biografia sobre o pioneiro das Assembleias de Deus em Santa Catarina descrevem a chamada Doutrina da Igreja, aspecto fundante do ethos pentecostal.

\begin{abstract}
A doutrina que o pastor André apreendeu do missionário Gunnar Vingrem foi posta em prática em todas as igrejas que ele pastoreava. Mulher tinha que se vestir com decência, como fala a Bíblia: Cabelos crescidos, vestidos cobrindo os joelhos e os braços com decotes pequenos e sem atrair a curiosidade de quem olhasse. Saias não justas, cobrindo o joelho também; não se devia usar pintura no rosto, nem pó de arroz, nem penteados, só cabelos presos. Não era permitido cruzar as pernas na igreja e esse hábito era para todos os lugares, onde a mulher crente estivesse.
\end{abstract}

O comportamento com os namorados era rígido. Depois do culto, não era permitido ao moço acompanhar a namorada. Namoro só na casa da moça, junto da família, nunca sozinhos. O namoro não podia ser longo. Tinha que ser rápido e logo acontecer o noivado e depois ir para o casamento. Os pais que não vigiavam os namoros das filhas eram chamados a atenção e, se não se corrigissem, eram todos passados por disciplinas com suspensão da comunhão. Só se casavam na igreja os noivos que obedeciam a ordem e a doutrina da igreja.

Na rua, as moças não podiam andar de braços dados com os noivos. Não deviam andar as gargalhadas em lugares públicos, pois tinham que mostrar seriedade em tudo. Não se deviam usar enfeites berrantes, com cores e babados que chamassem atenção. Nada de anel de enfeites ou pulseiras, só relógio de pulso e tudo muito discreto, nem passadeiras brilhantes nos cabelos. Tudo com a maior simplicidade sem ostentação.

Os homens não podiam subir no púlpito e nem pregar a palavra sem paletó e gravata. Não deviam usar bermudas ou calça curta. Os meninos até 12 anos usavam calças curtas. Depois dessa idade, era ensinado que na igreja tinham que ir de calças compridas. Nem homem ou mulher podia usar roupas transparentes. Nem cigarros ou bebida alcoólica entrava na boca dos crentes, demais vícios também não. E assim eram obedecido todas as doutrinas da igreja, pois tinham base na bíblia.

O pastor era dito como a pessoa de mais respeito. Ele vigiava até nos cultos o comportamento de todos. Tanto adultos como crianças eram chamados a atenção até durante os cultos se o comportamento fosse mal. Não deviam os jovens crentes frequentar festas do povo incrédulo, nem namorar incrédulo, isto era obedecido com rigor e temor a Deus. Os crentes usavam o rádio só para ouvir o noticiário e ao terminar era desligado para não ouvirem musicas profana. Aos filhos de crentes era proibido jogar bola (ADAMI; SILVA 2011 p. 67-69).

Freston (1993) irá afirmar que esta influência dos missionários não ficará restrita a regras de comportamentos, mas também à estrutura organizacional da instituição. Irá produzir uma junção entre o controle e à disciplina imposta pelos missionários suecos com o oligarquismo e 
coronelismo nordestino. Segundo ele a organização da IEAD é "uma complexa teia de redes compostas de igrejas-mães e igrejas e congregações dependentes" (FRESTON, 1993, p. 72.).

As disputas políticas internas e discussões doutrinárias não encerraram-se em 1930. As cisões e divisões acompanharam a denominação fazendo surgir dela novas convenções ${ }^{2}$, sendo que as mais importantes são: CGADB - Convenção Geral das Assembleias de Deus no Brasil, o Ministério Madureira, cisão ocorrida em 1985, liderada agora por Manoel Ferreira; Ministério São Cristovão, liderado pelo pastor Túlio Ferreira.

\section{ORGANIZAÇÃO INTERNA DA IGREJA EVANGELICA ASSEMBLEIA DE DEUS}

Como vimos acima, a IEAD é organizada em âmbito nacional em uma convenção, denominada Convenção Geral das Assembleias de Deus - CGADB. A CGADB é uma Associação de Igrejas, órgão máximo dentro da organização da Igreja de caráter burocrático e deliberativo, porém, seu poder é enfraquecido, pois ela não possui poder de imposição de suas decisões às convenções estaduais e locais. Seu surgimento deu em razão de disputas políticas entre os principais líderes e divergências doutrinárias na década de 1930. Historicamente ocorreram quarenta assembleias gerais, sempre ocorrendo a cada dois anos.

A organização estadual da IEAD se dá a partir das Convenções. Hoje, há 52 Convenções Estaduais filiadas a $\mathrm{CCADB}^{3}$, sendo que no exterior há uma nos Estados Unidos e uma do Japão. Em Santa Catarina a principal convenção das Assembleias de Deus é a Convenção das Assembleias de Deus de Santa Catarina e Sul do Oeste do Paraná - CIADESCP.

\footnotetext{
${ }^{2}$ A última cisão importante ocorrida no interior da CGADB foi a saída do Pastor Silas Malafaia em 2011, que desfiliouse e organizou um ministério a partir na IEAD da Penha, mudando o nome para IEAD Vitória em Cristo.

${ }^{3}$ Ainda na estrutura da CGADB há os Conselhos, sendo eles: Conselho Consultivo; Conselhos Regionais; Conselho Administrativo da CPAD; Conselho Fiscal; Conselho de Ética e Disciplina; Conselho de Educação e Cultura; Conselho de Doutrina; Conselho de Ação Social; Conselho de Capelania; Conselho de Comunicação e Imprensa; Conselho Político; Conselho de Missões (CGADB, 2007, Art. 49.).
} 


\section{CONVENÇÃO DAS ASSEMBLEIAS DE DEUS DE SANTA CATARINA E SUL DO OESTE DO PARANÁ - CIADESCP}

Segundo o estatuto da entidade, o objetivo da CIADESCP é a pregação do evangelho estabelecendo orientação administrativa, eclesiástica, litúrgica e doutrinárias as igrejas e pastores ligadas a ela 4 .

A sua organização interna se dá a partir de uma diretoria que é denominada de Junta Executiva composta por 7 (sete) membros pastores eleitos por biênios, sendo presidente, $1^{\circ}$ e $2^{\circ}$ presidente, $1^{\circ}$ e $2^{\circ}$ secretário e $1^{\circ}$ e $2^{\circ}$ tesoureiro. Além da Junta Executiva fazem parte da estrutura organizacional da CIADESCP departamentos e conselhos que tem como objetivo assessorar na administração da entidade 5 .

Ligados a CIADESCP estão as Igrejas membros, que segundo o estatuto da instituição são “organizações religiosas que aceitam a condição de igreja uma e indivisível, recebendo e acatando, em todos os seus setores de atividades, as orientações administrativas, litúrgicas e doutrinárias" (Art. 4, CIADESCP, 2011).

As igrejas membros, conforme o estatuto da CIADESCP, devem adequar seus estatutos, administração, doutrina e liturgia às deliberações da organização estadual. Para a melhor compreensão da organização interna e da hierarquia dos campos eclesiásticos da CIADESCP, construímos abaixo, um organograma da instituição em forma de quadro.

As igrejas membros, por sua vez, são organizadas a partir de uma igreja sede em cada cidade, sendo que em cidades menores é possível ter duas cidades agrupadas em um só campo

\footnotetext{
${ }^{4}$ A CIADESCP tem como objetivo primordial a pregação do evangelho, estabelecendo, orientação administrativa, eclesiástica, litúrgica e doutrinaria as igrejas de sua jurisdição, e ao Pastor Presidente, Pastores Auxiliares, Evangelistas e Presbíteros (Ministros/Sacerdotes), estabelecer as diretrizes e fiscalizar as assistências sociais assistência educacional, todo o tipo de beneficência praticado pelas igrejas e de entidades ligadas a mesma, com o fim de erradicar a pobreza e a marginalização, sem preconceitos de origem, raça, sexo, cor, idade, observando os preceitos da dignidade da pessoa humana; respeitando e fazendo respeitar a independência e soberania nacional. Podendo inclusive promover a execução de radiofusão através de sons, imagens, desde que devidamente autorizados pelo poder competente (CIADESCP, 2011, Art $2^{\circ}$ ).

${ }^{5}$ São eles: UMADESCP - União da Mocidade da Assembleia de Deus de Santa Catarina e Sul do Oeste do Paraná; UMADESSCP - União das Esposas dos Ministros da Assembleia de Deus de Santa Catarina e Sul do Oeste do Paraná; CEC - Conselho de Educação e Cultura; DECOM - Departamento de Comunicação; UAADESCP - União dos Adolescentes da Assembleia de Deus de Santa Catarina e Sul do Oeste do Paraná; FATASCP - Fundo de Amparo Temporário; Conselho Jurídico; Conselho de Ética Ministerial; Comissão Pró-política.
} 
eclesiástico, com um pastor presidente que coordena os distritos e congregações nos bairros. A convenção conta com cerca de 247 igrejas sedes associadas a ela. Estas igrejas membros são organizadas em 13 regiões eclesiásticas, distribuídas por regiões geográficas em todo o estado de Santa Catarina e Sul do Oeste do Paraná.

\section{CONSELHO POLÍTICO DA CIADESCP: O nepotismo entre representantes e legitimados}

Em Santa Catarina a organização da CIADESCP possui em sua estrutura o Conselho Político que é chamado de Comissão Pró-Política da CIADESCP. Esta comissão é composta por presidente, vice-presidente, primeiro e segundo secretários além de um relator. Também fazem parte das reuniões da Comissão Pró-Política os dois deputados estaduais e seus assessores. Sua função é orientar a Junta Executiva e os pastores da convenção nos assuntos referentes à participação política.

Em uma cartilha distribuída à pastores da instituição, o conselho registra que sua intenção em utilizar a participação política como ferramenta é para influenciar os valores, a moral e a cultura da sociedade em geral. A instituição se auto-denomina reserva moral da sociedade ${ }^{6}$.

A escolha ou orientação pelo apoio institucional da IEAD para os candidatos não se restringe ao legislativo, mas acontece também nos cargos para o executivo, mesmo que não haja um candidato pertencente à instituição.

Geovania de Sá (PSDB) atualmente representa a CIADESCP na Câmara dos Deputados, a deputada foi eleita com 52.757, porém, não recebeu apoio formal do conselho político, que na eleição de 2014, decidiu apoiar Jovino Cardoso (DEM). O grupo já foi representado por Orlando Pacheco do Partido da Frente Liberal (PFL) que em 1986 conquistou 42 mil votos. Depois foi representada pelo ex-deputado Adelor Vieira (PMDB). Vieira chegou a ser coordenador da bancada evangélica.

\footnotetext{
${ }^{6}$ Louvamos a Deus pela visão abrangente da Convenção das Assembleias de Deus em Santa Catarina, que tem oportunizado aos membros desta conceituada igreja o uso de uma ferramenta chamada "política" como instrumento fundamental para a implantação dos princípios e valores no contesto da sociedade. Os meios de comunicações têm expostos de forma compulsiva aspectos relacionados à degeneração moral da nossa cultura. Mas há um remanescente, uma "reserva moral" homens e mulheres que cultivam em suas vidas a excelência da vida Cristã, estando habilitados a ocuparem um espaço nos poderes executivos ou legislativo municipal, para fazerem a diferença (CIADESCP, 2012 p.2).
} 
A Assembleia Legislativa de Santa Catarina - ALESC conta desde a redemocratização com a presença de parlamentares pentecostais, sendo que a IEAD contou sempre no mínimo com um representante. Na atual legislatura há três deputados na Bancada Evangélica. ${ }^{7}$ A IEAD conta neste momento com dois parlamentares, os Deputados Ismael dos Santos e Kennedy Nunes, ambos do PSD. (Escrever parágrafo sobre Geovana de Sá)

O apoio e legitimação político-religiosa por parte do Conselho Político da CIADESCP não se restringe na hora do voto, mas o relacionamento entre autoridades políticas e a liderança religiosa muitas vezes excede o período eleitoral. As autoridades políticas são convidadas a participar de reuniões e atividades religiosas onde sua presença é supervalorizada, sendo muitas vezes convidados a falarem aos fiéis.

Esse fato lembra Bourdieu (2009) ao afirmar que "A Igreja contribui para a manutenção da ordem política, ou melhor, para o reforço simbólico das divisões desta ordem, pela consecução de sua função específica, qual seja a de contribuir para a manutenção da ordem simbólica" (BOURDIEU, 2009, p. 70).

Esse fato lembra Bourdieu (2009) ao afirmar que "A Igreja contribui para a manutenção da ordem política, ou melhor, para o reforço simbólico das divisões desta ordem, pela consecução de sua função específica, qual seja a de contribuir para a manutenção da ordem simbólica" (BOURDIEU, 2009, p. 70).

\section{A ESCOLHA DOS “UNGIDOS”}

As escolhas dos candidatos a serem apoiados pela Comissão Pró-Política da CIADESCP segundo nossos entrevistados acontecem de duas formas. Quando o pleito é estadual, realiza-se um referendo estadualizado entre os pastores ligados a CIADESCP. Quando o pleito é municipal o critério fica a cargo do pastor local. Segundo uma liderança entrevistada, a escolha do candidato não se dá a partir de bandeiras ou por princípios ideológicos, mas pela capacidade de eleição do candidato. "A escolha dos candidatos hoje da Igreja visa muito mais o potencial de eleição do que alguma coisa ideológica, ou próprias bandeiras". (grifo nosso) Demonstração de 
instrumentalização política. Os entrevistados afirmaram que a instituição não proíbe um eventual candidato não apoiado pela instituição de fazer campanha entre seus membros.

\begin{abstract}
As coisas acontecem praticamente quase que no natural. A pessoa já tem uma influência, a pessoa já concorreu a alguma coisa, ele já tem um lastro. Dentro do segmento onde ele está congregando, na congregação ou na Igreja. E este lastro que ele tem vai dando no caso condições de ele ser uma pessoa que venha representar a Igreja. Depois então a Igreja também aponta o seu candidato, mas não fecha a porta para outros. Tem é claro, diversos tipos de escolha. Nós não temos assim uma maneira única, nós temos algumas Igrejas, que foi feito uma votação interna, os outros candidatos concordaram: se não ganhassem então eles não sairiam. Então quando chega este consenso, eu acho que é essa forma é uma boa. Agora quando não há consenso, [...] Então a Igreja vai ver quem mais tem condições e diz: Irmãos há esse, esse, e esse candidato. Agora nós gostaríamos que os irmãos na medida do possível votassem nessa pessoa que ouve o ministério local. Porque quando eu falo o ministério local, são os presbítero ou diáconos e os auxiliares de uma igreja, que representa a igreja num todo (FONTE A).
\end{abstract}

Sobre a escolha dos candidatos oficiais da CIADESCP em nossas entrevistas, houve também o relato de que os critérios de escolhas dos candidatos, internamente nem sempre se dá de forma democrática. As lideranças políticas relataram situações de nepotismo, favorecimento de candidatos por conta de amizades com candidatos e até uso de templos e veículos da Igreja em campanhas eleitorais.

\begin{abstract}
Na nossa cidade historicamente nas últimas eleições com exceção desta última 2012, o pastor sempre bancou o nome de alguns, por amizade, e até por nepotismo. Em 2008, o candidato oficial da Assembleia de Deus era o genro do pastor. O que nós observamos é que havia um constrangimento em cima dos pastores distritais para que fizessem campanha para esse candidato, o candidato do presidente. Isso naturalmente causou uma frustração e até certa magoa dos demais candidatos. Porque a gente entende que o membro é livre por opção ideológica ou simpatia de regionalidade. E na época eu também fui candidato, e eu também tive dificuldade de ter apoio dentro da Igreja, sobretudo na região que eu moro, porque os pastores foram orientados a fazer campanha com exclusividade para o candidato da Assembleia... Em todos os templos tinha uma quantidade muito boa de material, todos os carros das lideranças com perfureide. (FONTE C).
\end{abstract}

A utilização do carisma religioso por parte de líderes religiosos para a eleição de familiares em cargos políticos é comum em meio a Bancada Evangélica, seja em nível local ou em nível nacional. O presidente da CGADB José Wellington é pai do Deputado Federal Paulo Freire do PR-SP e da Deputada Estadual Marta Costa do Partido Social Democrata (PSD-SP) em São Paulo. A 
vereadora também é suplente do Senador Aloyso Nunes do Partido da Social Democracia Brasileira (PSDB-SP). A principal liderança de oposição ao José Wellington, o Pr. Samuel Câmara, pastor da Assembleia de Deus de Belém do Pará é irmão do Deputado Federal Silas Câmara do Partido Social Cristã (PSC-AM). É Deputado Federal pelo Estado do Amazonas e cunhado da Deputada Antônia Lúcia do PSC-AC, Deputada Federal pelo Estado do Acre. Caso raro de marido e mulher serem deputados federais, um pelo Estado de Amazonas e outro pelo Acre. No Estado de Minas Gerais o Deputado Isaias Silvestre do Partido Socialista Brasileiro (PSB-MG) é filho do Pr. Ancelmo Silvestre, que por 51 anos foi Presidente da Convenção dos Ministros da Assembleia de Deus do Estado de Minas Gerais (COMADEMG).

No Rio de Janeiro, o Deputado Federal Filipe Pereira do PSC é filho do Pr. Everaldo Pereira, pastor da Assembleia de Deus e vice - presidente nacional do PSC, candidato a presidente no pleito de 2014. Ainda no Rio de Janeiro o Pr. Silas Malafaia elegeu seu irmão o Deputado Estadual Samuel Malafaia do PSD. Em Santa Catarina, o Deputado Ismael dos Santos (PSD) é filho do pastor Nilton dos Santos, presidente de honra da CIADESCP e da IEAD de Blumenau.

Outra característica da Bancada Evangélica é a participação dos chamados "artistas gospel". Uma considerável parcela dos políticos pertencentes à bancada possue alguma carreira como cantor ou pregador itinerante ${ }^{8}$. No Congresso, os Deputados Marcos Feliciano e Takayama do PSC são pastores itinerantes. A Deputada Federal Lauriete Rodrigues do PSC-ES é cantora gospel desde a infância e possui 27 CDs gravados, 04 DVDs. Seu Esposo, o Senador Magno Malta do PR-ES é cantor. No Paraná a Deputada Estadual Mara Lima do PSDB-PR também é cantora gospel por mais de 30 anos, possui 36 CDs e 2 DVDs gravados.

Entre os agentes políticos que entrevistamos, dois são cantores e um é escritor, sendo que os três relataram que a carreira como cantor, facilita na busca de votos. O Deputado Kennedy Nunes do PSD é jornalista, filho de missionários e faz parte de um grupo tradicional de música evangélica chamado Dedos de Davi. Canta e toca harpa Paraguaia. A irmã do Deputado Kennedy Nunnes, Zilnete Nunes também é cantora e foi vereadora em Joinville na legislatura 2009-2012. Atualmente é suplente de Vereador em Joinville. O Vereador Lionilson Correia do Partido dos

\footnotetext{
${ }^{8}$ O pregador itinerante é categoria de pastor ou missionário é convidado para participar de eventos chamados de congressos ou cultos especiais como preletor. São famosos e valorizados por portarem um perfil vibrante e mobilizador dos fieis.. Os pregadores itinerantes pentecostais assemelham-se com a descrição de Bourdieu faz dos profetas dentro do campo religioso. O Deputado Marcos Feliciano do PSC de São Paulo é um importante pregador itinerante.
} 
Trabalhadores (PT) de Joinville é vocalista do grupo musical Getsemane. O Deputado Ismael dos Santos PSD-SC é pastor e escritor de livros religiosos. É filho de pastor de honra da CIADESC, além de ser irmão do vice-presidente da entidade. Fez sua carreira quase que prioritariamente com votos da igreja. O político possui uma estratégia de distribuição de literatura religiosa como forma de busca do voto. Segundo o próprio deputado, em entrevista a este projeto dissertativo, já distribuiu cerca de quinhentos mil livros religiosos. Em Blumenau, o Vereador Marcos da Rosa do DEM apresenta um programa de TV em um canal local onde faz preleções pentecostais.

Acontece aqui a atuação do mecanismo político eleitoral-religioso operado pelos lideres políticos pentecostais, que utilizam-se do carisma adquirido no campo religioso, para atuar no campo político. Bourdieu (2009), lembra que em alguns casos, os dos profetas, os atores religiosos ganham uma eficácia simbólica com força de legitimação e absolutização. Assim, os agentes políticos pentecostais, acreditam, e se fazem acreditar que possuem uma missão especial, portanto divina na atuação política.

Assim, talvez seja preciso reservar o nome carisma para designar as propriedades simbólicas (em primeiro lugar, a eficácia simbólica) que se agregam aos agentes religiosos na medida em que aderem à ideologia do carisma, isto é, o poder simbólico que lhes confere o fato de acreditarem em seu próprio poder simbólico (BOURDIEU, 2009, p. 55).

Estes fatos comprovam a clássica descrição de Frenton (1993), sobre o modelo de governo eclesiástico da IEAD como oligárquico e caudilhesco. Uma junção do ethos trazido pelos missionários suecos caracterizados pela centralização na figura dos missionários com o coronelismo brasileiro. O resultado é a centralização na figura do poder do Pastor-presidente, que sozinho manipula as decisões de todo o campo religioso transformando e cacifando este poder (religioso) em influências sobre o território através do poder político. Estas características do governo eclesiástico assembleiano, (centralizador, autoritário e gerontocrático) quando expostos a relacionamento com a lógica eleitoral brasileira, sucumbem aos seus deslizes, sobretudo, no que se refere ao clientelismo como forma de fidelização eleitoral:

Porque eles veem no parlamentar a possibilidade dele ser aquele agente pra bancar um ônibus para a Igreja, ajudar a trazer um pastor de outra cidade, as despesas que eles 
cobram avião, de hotel. Eles veem no parlamentar essa forma assistencialista. Se é pra fazer uma festa que eles vão ver um desdobramento de despesas com guloseimas, com refrigerantes, que também vem do parlamentar. Não um agente político, mas um agente filantrópico neste momento. Porque, a questão dogmática ainda é muito forte dentro da Igreja. A mistura entre o real papel do vereador, o legislador, e o assistencialista. E cada vez mais a região é desassistida, aumenta o assistencialismo (FONTE C).

A partir dos dados acima podemos concluir que o voto "pentecostal" opera como uma verdadeira legitimação carismática descrita por Weber (1999), uma vez que a dominação política é dependente do carisma por obediência ou por convicção. Nesta forma de dominação segundo o sociólogo alemão, diferente da dominação legal onde há uma crença na norma ou nas regras, a dominação carismática se dá pelo fato da crença, no chamado ou na tradição. A figura do pastor repassa o poder ou privilégio, do carisma a partir do seu poder divino, construído na esfera religiosa para o indicado. Segundo Weber o domínio nestes casos é "inteiramente independente das qualidades pessoais" do legitimado (WEBER, 1999, p. 139).

\section{ENSAIANDO UMA CONCLUSÃO}

Durante o mergulho que realizamos no interior do grupo pesquisado, percebemos que o início da trajetória do grupo é marcado pela característica de grupo religioso de negação do mundo, sobretudo, pela forte disciplina no comportamento pessoal, com proibição de envolvimento dos fiéis com música popular, dança ou futebol considerado como "coisas do mundo". Neste tempo também a participação política era proibida, uma vez que o fiel deveria preocupar-se com a busca do reino do céu.

Conforme vai alterando a vida nacional as características do grupo religioso também se modificam com inúmeras transformações, sobretudo no que refere ao seu crescimento, a provocar uma transformação direta na sua teologia. A compreensão da alteração deste discurso que esta chave de interpretação da ascensão dos pentecostais no Brasil seja em números de fiéis como também no crescente protagonismo social e político.

Conforme vimos acima uma característica marcante no perfil assembleiano é a organização interna da instituição que centraliza o poder na figura do Pastor Presidente formando 
em todo o Brasil, a partir de Convenções e Igrejas sedes, uma federação de oligarquias religiosas regionais, com característica de capilaridade social uma vez que estão situadas nas periferias das cidades.

Do ponto de vista político buscamos compreender como se dá o processo de legitimação no interior do campo pentecostal onde com o advento da redemocratização e da constituição de 1988 os pentecostais lançam-se na vida política constituindo a Bancada Religiosa. Com a organização interna assembleiana fortemente centralizada nas figuras dos seus líderes, a Bancada Política reedita o fenômeno do coronelismo e do assistencialismo político, transformando e instrumentalizando seus candidatos em agentes políticos a serviço da instituição ou de suas lideranças regionais. É fortemente marcada a prática de indicação de candidatos que são filhos ou familiares de lideranças religiosas. Outro fato recorrente é a participação de lideranças do mundo gospel, cantores e pastores itinerantes, que transformam seus carismas religiosos em capital político. Numa clara utilização do carisma religioso carisma adquirido no campo religioso, para atuar no campo político. Um mecanismo não só político eleitoral mas de produção e reprodução de uma nova elite política.

\section{REFERÊNCIAS}

ALMEIDA, Abraão de. História das Assembleias de Deus no Brasil - 2. Ed - Rio de Janeiro: CPAD, 1982.

BOURDIEU. Pierre. A gênese e estrutura do campo religioso. A economia das trocas simbólicas. Org. Sergio Micelli. Editora Perspectiva - São Paulo, 2009

As estruturas sociais da economia. Lisboa : Instituto Piaget, 2001.

O poder simbólico $16^{\circ}$ ed. - Rio de Janeiro: Bertrand Brasil, 2012.

CGADB. Estatuto. Porto Alegre - RS, 2007. 
CIADESCP. Estatuto da CIADESCP. Itajai - SC, 2011

Cartilha de orientação interna: comissão pro-política - Convenção das Igrejas Evangélicas de Santa Cataria e Sudoeste do Paraná. Itajai - SC, 2012

d ÁVILA, Edson. A Assembléia de Deus no Brasil e a política: Uma Leitura a Partir do mensageiro da Paz. Dissertação de Mestrado - Universidade de São Paulo. Faculdade de Filosofia e Ciências da Religião, Curso de Pós Graduação em Ciências da Religião. São Bernardo do Campo, 2006.

FRESTON. Paul. Protestante e Politica no Brasil: da constituinte ao impeachment. Tese Doutorado. Unicamp. 1993

LOPES, Denis Vãnio. A Organização Eclesiástica da Assembleia de Deus em Canoas/RS.

Dissertação mestrado - Pontifícia Universidade Católica - PUC RS. 2008.

MAFRA, Clara. Os Evangélicos. Rio de Janeiro - RJ: Ed Jorge Zahar Ed. 2001

TOCQUEVILLE. Alexis de A democracia na America - Belo Horizonte - MG. Ed. Itatiaia: 1987.

WEBER, Max. Rejeições religiosas do mundo e suas direções. Os Economistas. Org. Mauricio Tragtenberg. Editora Nova Cultural: São Paulo - SP, 1997

- Teoria do los estádios y direcciones del rechazo religioso del mundo. Ensayos de sociologia de la religion. Madrid: Taurus, 1998, p.534-535.

. Economia e sociedade: fundamentos da sociologia compreensiva. 3. ed. Brasília: UnB, 1994, vol.1.

. A ética protestante e o espírito do capitalismo. Editora Martin Claret. 2005 